\title{
Coreografar Historias da arte da performance Moments. A History of Performance in 10 Acts
}

\author{
ANNE BÉNICHOU \\ TRADUÇÃO: SAMUEL DE JESUS \\ REVISÃO DA TRADUÇÃO: ANAHY JORGE
}

N umerosas exposições têm sido recentemente organizadas em torno de um encontro da performance e da dança contemporânea. As instituições tradicionalmente dedicadas às artes visuais abrem-se a performance, ao mesmo tempo que a dança. Os coreógrafos cada vez mais numerosos preferem as galerias dos museus e dos centros de exposição que a sala de espetáculo tradicional. Esses fenômenos podem contribuir a renovar os modos de pensar a memória e a transmissão da arte da performance?

Há muito anos as noções do aqui e do agora, de presença do performer, de co-presença do público, de experiência direta, não midiatizada, singular, tinham sido sobrevalorizadas em relação a performance, e limitaram muitas vezes a reflexão em relação a sua transmissão: que elas surgem a partir dos documentos ou como formas de reiterações, por uma questão de legitimidade ou de não-legitimidade das diferentes estratégias privilegiadas.

Os debates que ocorreram nesses últimos anos em torno das recreações de obras performativas do passado nos contextos de museus (ou pelo menos institucional) - reenactments, re-performances, recriações, etc. - reconduziram esse dualismo que conheceu o seu paroxismo em 2010, durante os debates que cercaram a exposição Marina Abramovíc: The artist is presente [Marina Abramovíc: A artista está presente]'. De um lado, reencontramos uma suspeição a respeito da documentação e uma reinvindicação do reenactment enquanto forma viva da transmissão das performances do passado. Desconfiamos da cultura arquivística, do domicílio dos documentos que ela opera, da fixação dos seus sentidos, do controle da sua difusão. Alguns associam o documento aos poderes políticos, econômicos, midiáticos, à autoridade do autor aos quais as 
práticas de retomada que privilegiam o corpo teriam a capacidade de resistir ${ }^{2}$. Do outro lado, rejeitamos o reenactment [reconstituição], ao benefício da exposição dos documentos e dos arquivos e de um restabelecimento das modalidades da sua apresentação. Recusamos os fenômenos de anacronismo que o reenactment induz, sua participação no quadro institucional, a mercadoria e o "espetáculo" das práticas performativas; criticamos ainda sua propensão em criar repertórios lá onde os artistas não o entendiam sempre assim.

Todavia, e essa é a minha hipótese, os encontros renovados da performance e da dança no seio de exposições permitiram de abrir e de dinamizar esse debate, de instaurar uma dialética que encoraja para ir além dessas dicotomias, acolhendo e favorecendo também os dissensos e as fricções. Num primeiro tempo, eu me esforçarei de precisar essa hipótese e de medir as incidências desse fenômeno sobre a transmissão das obras performativas. Abordarei depois a exposição Moments. A History of Performance in 10 Acts [Momentos. Uma Historia da Performance em 10 atos] organizada em 2012 no Zentrum für Kunst und Medientechnologie (ZKM) em Karlsruhe, na Alemanha3 , exposição esta que me parece exemplaria das mutações que eu tento de delimitar.

\section{Os encontros renovados da dança e da performance}

Ao longo da última década, os museus e os centros de exposição, tradicionalmente consagrados às artes visuais, abrem-se à dança ao mesmo tempo do que á performance. Numerosas e grandes exposições têm sido organizadas em torno do encontro dessas duas disciplinas. Move. Choreographing You. Art and Dance since the 1960s ${ }^{4}$ [ Coreografar você. Arte e Dancça desde os anos 1960 ], apresentada em Londres, Munique e Dusseldorf em 2011 declina os cruzamentos entre as artes visuais e a dança ao longo das últimas cinco décadas. Ou ainda, em 2011-2012, no Centro Georges Pompidou, Danser sa vie. Art et danse de 1900 à nos jours 5 [Dançar sua vida. Arte e Dança de 1900 até hoje] trata das ressonâncias entre as artes visuais e a dança todo ao longo do século XX. A Tate Modern de Londres, em seus tanques inaugurados em 2012, e o Museu of Modern Art de Nova Iorque (MoMA), junto com a sua "Performance Series" iniciando em 2009, propunham uma programação ampla de arte da performance e de dança contemporânea. 
Todavia, as reflexões e os debates os mais interessantes não parecem se concentrar em torno da questão da interdisciplinaridade. Várias exposições que privilegiam o âmbito interdisciplinar, insistindo sobre as sobreposições genealógicas das duas disciplinas, oscilam entre os regimes tradicionais da exposição e do espetáculo, próprias do museu e do teatro. Os corpus de "objetos" são expostos segundo um protocolo museológico tradicional: alguns são promovidos à categoria de obras de arte, outros são relegados a uma função encilaria. Enquanto na periferia, as reativações de obras coreográficas e performativas intervêm como uma mais-valia da exposição, segundo uma lógica de evento e de espetáculo.

$\mathrm{O}$ interesse desses encontros da dança e da performance no quadro de exposições parece ocupar um outro lugar: na renovação da maneira de pensar a memória e a transição das obras, estreitamente articulada a uma reavaliação do museu que nós assistimos: o museu como lugar de fábrica das histórias das artes e como instituição pública. À lógica do arquivo substitui-se a lógica do repertório que recoloca o corpo nas suas dimensões individuais, afetivas, coletivas e políticas, no coração do processo de transmissão.

\section{Pensar de outro modo a memória das obras}

Os anos 1990 foram o testemunho de um reinvestimento sem precedente dos métodos, das práticas e dos lugares das memórias da dança. Se os fenômenos de reconstrução, de retomada, de anotação, de captação são inscritos na tradição da dança, eles tornaram-se recentemente sujeito, matéria e motor de criação coreográfica. André Lepecki anota que: "os dançarinos voltam mais em mais na direção das suas marcas históricas e da dança, para achar o objeto da sua busca". O retorno torna-se uma forma de experimentação contemporânea.

Essas experimentações rearticulam a memória de arquivo [as marcas materiais que cercam uma obra coreográfica e suas múltiplas interpretações] e a memória corporal e cinestésica que se transmitem oralmente de um dançarino ao outro, segundo os fenômenos de excorporação e de incorporação. No meio de vários exemplos, em 2008, Martin Nachbar reinterpreta os Affectos [Afetos] humanos de Dore Hoyer (1962) explicitando e problematizando, desde a abertura da peça, suas ligações com os arquivos documentais e vivos, desenhando num quadro os raios de relações entre as marcas, os arquivos e as testemunhas. 
Em After Trio A [Depois do Trio A] (2012), Andrea Bozić encena uma dupla transmissão de Trio A (1966) de Yvonne Rainer. Um primeiro performer aprende a peça assistindo num monitor o filme realizado em 1978 e imitando Rainer, quanto um segundo dançarino reproduz os gestos do primeiro, e isso até o ponto de assimilar da peça. Além desse duplo registro de transmissão, After Trio A propõe uma reflexão sobre a linguagem coreográfica de Rainer, o seu continuum gestual e suas ligações a imagem fotográfica e fílmica. Essas experiências não alcançam a fixar a dança original, mas ao contrário a reinventá-la, a ativar as virtualidades que a obra contém em reserva, retomando as palavras de Lepecki (LEPECKI, 2010).

É por isso que uma grande parte dessas pesquisas investiga igualmente as possibilidades da notação. Mesmo se seu uso não se generalizou e que nenhum código universal não foi estabelecido, a notação da dança localiza-se ao século XV. Ao longo das últimas décadas, vários coreógrafos recorreram aos diferentes sistemas notacionais para por em jogo questões fundamentais. Assim, o Quatuor Albrecht Knust ${ }^{6}$ questiona a autonomia da obra coreográfica em relação ao seu autor e sua separação do corpo originário incarnado (o primeiro intérprete). William Forsythe explora os desenvolvimentos numéricos dos sistemas de anotação e dos seus usos possíveis com fins criativos, mais do que memoriais.

Nesses projetos, a anotação consiste menos em fixar a obra, definir nela as propriedades constitutivas ou a identidade específica, para falar como Nelson Goodman e Gérard Genette, do que ligar duas operações, a tradução e a invenção, retomando as reflexões de Simon Hecquet e de Sabine Prokhoris. É a razão pela qual eu aproximaria a anotação da noção de diagrama (ou de diagramática) que Gilles Deleuze elaborou a partir do pensamento de Michel Foucault e da pintura de Francis Bacon. Um diagrama é um conjunto operatório cuja função consiste em "introduzir as possibilidades de fato"; ele é orientado na direção de um destino. "A história das formas, arquivo, é duplicada de um destino das forças, diagrama". Esse "duplica a história com um destino", escreve Deleuze em Foucault.

Essas experiências de retorno ás obras do passado articulam estreitamente o live, o arquivo e o diagrama; elas tendem igualmente a aproximar os arquivos do diagramático porque nele, os documentos estão pensados não mais como marcas, mas como componentes de partituras. Desde então, eles reencontram um uso que freia os processos de fetichismo operados pelas instituições oriundas das belas-artes. 
A riqueza desse questionamento e sua intrusão nas instituições dedicadas às artes visuais trouxeram um novo impulso aos debates sobre a transmissão da performance e incitaram as instituições responsáveis a iniciar uma reavaliação crítica. Boris Charmatz formula muito bem essa revisão com o Museu da Dança, uma entidade fictícia numa instituição real, destinada a criação, o Centre Chorégraphique de Rennes et de Bretagne, que lhe permite de explorar as ligações entre a criação coreográfica, a noção de arquivo e de museu. Questionar as noções de marca, de documento, de arquivo, de acervo de museu, de patrimônio, instaurar uma tensão entre as convenções da exposição e o corpo dançante, por em obra um arquivo vivo, tais são as principais orientações do seu programa de criação.

\section{Desfazer as convenções da exposição}

A intrusão dessas práticas coreográficas no museu contribui a repensar a exposição e suas convenções. Retrospective de Xavier Le Roy [Retrospectiva de Xavier Le Roy] é um exem$\mathrm{plo}^{7}$. Essa retomada dos soli do coreógrafo, criados entre 1994 e 2010, por uma equipe de dançarinos e nos espaços dos museus, desvia o formato da retrospectiva, tanto do ponto de vista da história da arte, quanto das estratégias curatoriais. Ela puxa, ainda mais, os limites do que pode ser uma exposição. Desprovida de quaisquer objetos, apresentando somente os corpos, o vivo, a corporeidade, Retrospective [Retrospectiva] oferece nenhuma representação parada ou provisoriamente fixa. Le Roy adaptou a coreografia às horas de abertura dos museus e à duração da exposição, instaurando uma sequência de dançarinos para que não haja nenhuma interrupção. O deslocamento da dança no museu articula aqui uma dupla interrogação: ela quebra as modalidades temporais do espetáculo, e problematiza correlatamente a duração da exposição substituindo á configuração estável de uma montagem o movimento dos corpos dançantes. Le Roy elaborou uma temporalidade complexa e heterogênea para evidenciar este paradoxo. Ele associou três abordagens: o tempo suspendido, parado, o do objeto de museu tradicional (a imobilidade das poses); o tempo cíclico que evoca a temporalidade dos vídeos e dos filmes que brincam, em loop, numa sala de exposição (sete sequências gestuais dançadas em loop); e o tempo linear, enquadrado por um início e um fim (as histórias pessoais que os performers narram pelo público em alternância com os gestos). O sistema que sustenta a coreografia permite brincar 
com essas três temporalidades simultaneamente, ao mesmo tempo de modo contínuo e descontínuo.

Regulada por partituras e protocolos de trabalho, Rétrospective é concebida por ser ativada em outros lugares e outros tempos. Apresentada no início em 2012 na Fundação Antoni Tapiés em Barcelona, ela foi reiterada sete vezes em dois anos, em contextos também diferentes como Rennes, Salvador da Bahia, Hamburgo, Rio de Janeiro, Cingapura, Paris, Nova Iorque, cada vez com dançarinos locais que se apropriam da proposta diferentemente. Um novo modo de produção da exposição emerge aqui. Mathieu Copeland fala graciosamente de "coreografar a exposição" (COPELAND e PELLEGRIN, 2013).

Enfim, Rétrospective questiona certo número de hierarquias sociais e de formas respeitosas de sociabilidade. Ela reinventa a relação ao espectador por meio de formas de chamada que o coloca no coração da obra. Nesse sentido, a partitura antecipa uma interrupção e um recomeço das sequências na chegada de novos visitantes, para acolhê-los e os significar que eles fazem plenamente parte da proposta. Quanto aos performers, eles são convidados a contextualizar um aspecto da dança em relação ao seu próprio percurso de intérprete e elaborar uma narrativa biográfica que eles entreguem ao espectador. Deixando assim a fala aos dançarinos, os convidando a produzir seu material coreográfico, Le Roy inverte a relação tradicional entre o coreógrafo e o intérprete (o primeiro, autor demiurgo; o segundo, instrumento ao serviço da sua criação), ele desloca o solo no terreno do coletivo. Le Roy problematiza um modelo de partilha e experimenta outros modos de estar-juntos.

\section{Experimentar os corpos coletivos e os modos de sociabilidade}

As relações do individual ao coletivo, as hierarquias entre coreógrafos e intérpretes, o estar-junto, o envolvimento do público consistem em tantas questões que mostram que, os museus questionam os modos de sociabilidade que eles colocam em ação enquanto instituições artísticas públicas através do coreográfico. Laurence Rassel, diretora da Fundação Antoni Tàpies que encomendou a Le Roy Rétrospective, explica que por meio dessa experiência ela desejava repensar o que poderia ser hoje uma instituição pública: quais são os desafios do 
que é nomeado hoje como o público em um museu de arte contemporânea? Qual tipo de contrato liga a instituição ao seu público? Como tornar tangíveis e perceptíveis essas interrogações, trazê-las á reflexão?

Essas interrogações pressuponham um bom número de instituições e de projetos que exploram as relações entre a exposição e o coreográfico. Em 2011, no Tanzfabrik à Berlin, o projeto Rehearsing Collectivity - Choreography Beyond Dan$\mathrm{ce}^{8} \quad$ [Coletividade da Repetição - Coreografia além da Dança] juntavam obras performativas, participativas e sonoras, sob o denominador comum de práticas "coreográficas no sentido estendido", ou seja, toda forma de organização e de movimentos corporais no tempo e no espaço permitindo de pensar e experimentar diferentes formas de estar-junto. $\mathrm{O}$ desafio dos três curadores, Elena Basteri, Emanuele Guidi et Elisa Ricci, consistiu em interrogar o social por meio do coreográfico e vice versa. Como a dimensão social e política implícita dentro do conceito de coletividades pode ser "vivenciada" nas práticas coreográficas e de curadoria? De que modo podemos explorar, através dos prismas do coreográfico e da exposição dos fenômenos (as relações de poder por exemplo), a liderança, a solidariedade, o populismo (GEORGIEVA, BASTERI e GUIDI, 2011)?

O artista Aldo Giannotti concebe um dispositivo, uma tribuna de madeira descentralizada em um espaço que perturbava o funcionamento previsto do espaço cênico e expositivo; entretanto Ingrid Hora confeccionou muletas coletivas. Ao usá-las, os espectadores formavam uma "coletividade performativa", um corpo coletivo que, através diversas atividades, experimentava o espectro entre o consensus e o dissensos: a ajuda, a colaboração, a dominação, os conflitos, as derrotas, as tomadas de poder, as perdas de controle, etc. (BASTERI, GUIDI et RICCI, 2012). As reflexões de um Giorgio Agamben ou de um Jean-Luc Nancy sobre a noção de comunidade estão aqui evidentes: a comunidade não se define a partir das propriedades comuns que compartilhariam os membros que a compõe, ela escolhe as "singularidades outras" além de toda reinvindicação indenitária (AGAMBEN, 1990). Ela questiona sobre seus limites e suas s linhas de partilha (NANCY, 1986), segundo um processo sem fim, jamais resolvido.

Repensar os modos de transmissão das obras, as convenções da exposição, as formas de sociabilidade, a dimensão pública das instituições de arte contemporânea, tais são os desafios da intrusão da dança contemporânea no museu, em suas formas as mais pertinentes e críticas. 


\section{Moments. A History of Performance in 10 Acts}

A exposição Moments. A History of Performance in 10 Acts é exemplar dessas interrogações. Ela propõe de pensar em atos de maneira transgeracional e dissensual a transmissão das obras performativas e coreográficas dos anos 1960 e 1970. Ela problematiza igualmente o contexto institucional do museu como espaço público de produção, de difusão e de preservação de uma história da performance. A sua análise detalhada permite de avaliar as capacidades e os limites das instituições como os museus a por em obra tais experiências de transmissão.

Organizada em 2012 no Zentrum für Kunst und Medientechnologie [ZKM] por Boris Charmatz, Sigrid Gareis e Georg Schöllhammer, a exposição trata das práticas performativas e coreográficas (da arte da performance e da postmodern dance) de dez artistas mulheres dos anos 1960 e 1970 que os curadores qualificam de "heróicas" (GAREIS, SCHÖLLHAMMER et WEIBEL, 2013). Algumas delas são muito conhecidas, outras pouco; elas vêm de diversos países (EUA, Jugoslávia, Argentina, Alemanha) e elas marcaram a história da performance ou da dança, e contribuíram em absolver as fronteiras: Marina Abramović, Graciela Carnevale, Simone Forti, Anna Halprin, Reinhild Hoffmann, Channa Horwitz, Lynn Hershman Leeson, Sanja Iveković, Adrian Piper e Yvonne Rainer. Essa história nominativa revelando a figura do artista em herói, mesmo no feminino, parece a priori datada. Mas, como eu o mostrarei, trata-se menos de produzir uma narrativa histórica do que atuar um repertório.

\section{Nem museu, nem teatro: uma exposição dispersa e evolutiva}

A cenografia concebida por Johannes Porsch descontrói da mesma vez as convenções do museu e do teatro. As barras tradicionalmente usadas no ZKM são permutadas do plano vertical ao plano horizontal. Essa permutação torna o espaço do museu em uma multidão de micro-espaços cênicos e em áreas de consulta e de trabalho. Ele abala o regime de olhar tradicional do museu herdado do modernismo. De fato, a cenografia de Moments [Momentos] substitui o face a face da obra e do espectador (a frontalidade e a absorção), ao imobilismo e a concentração que a experiência estética modernista exige, o deslocamento, a descentralização, a distração, a atenção para eventos periféricos. O olhar em ressalto evoca mais 
uma atividade intelectual (o ofício) ou manual (uma mesa de trabalho) do que a contemplação estética. Essa cenografia não se conforma também ao regime de visualidade tradicional do teatro segundo o qual os espectadores permanecem imóveis e silenciosos do início ao fim do espetáculo. Os organizadores de Moments multiplicaram as cenas para que as ações e as atividades acontecerem simultaneamente, que os visitantes deslocam-se constantemente e se dispersam a vontade, segundo os seus interesses.

Moments é evolutiva. Ela abre e fecha completamente vazia. O primeiro dia, os planos horizontais estão deixados virgens; no momento do encerramento, eles estão recobertos de branco. Quatro frases se sucedem, cada uma anunciando um momento do processo de transmissão: Act - Stage and Display ; "Re-Act - Interpretative Appropriation in the Artistic Laboratory", "Post-Production - Film Editing"; "Remembering the Act - The Performative Mediation of the Exhibition Process by Artistic Witnesses".

Ao longo da primeira frase, as dez artistas concebem a disposição dos documentos que elas tinham selecionado nos seus acervos de arquivos pessoais ou em algumas coleções de diversas instituições. Elas ministram igualmente conferências e ateliês, por fim de articular a transmissão arquivística com uma memória oral e cinestésica. Por exemplo: uma discussão pública com Channa Horwitz ou um ateliê com Simone Forti. Ao invés de expor um saber sobre a história da performance que já seria constituída, os curadores preferem elaborar um dispositivo propício a provocar experiências elas mesmas susceptíveis de gerir formas de conhecimento. Essa postura responde a orientação que o diretor do ZKM, Peter Weibel, privilegia desde 1999 e que consiste em transformar a sua instituição em um "museu performativo", ou seja, em um dispositivo permitindo de tornar em atos formas de saber.

A segunda frase é dedicada a um laboratório artístico confiado ao coreógrafo Boris Charmatz. Ele solicitou dez artistas e teóricos do mundo da arte para "refletir em atos" sobre os usos possíveis desses arquivos ${ }^{10}$ : os coreógrafos, sobretudo, mas também um arquiteto, um diretor, um violonista. O laboratório desenrola-se em frente da câmera da artista israelense Ruti Sela. Essa foi convidada para realizar um filme cujo estatuto não consistiria, todavia em um documentário sobre a exposição, mas em uma obra à parte. Montado no local ao longo da fase seguinte de pós-produção, ele encontra-se simultaneamente integrado na exposição na qual ele ocupa um 
lugar importante. Enfim, a fala é dada a dez estudantes de várias escolas de arte europeias que atuaram enquanto observadores durante toda a exposição. Eles são chamados para testemunhar "em atos" das suas experiências através das atividades de mediação com o público, das performances que dialogam com os documentos expostos, e diversas formas de intervenção. Assim, a exposição dos traços, a sua documentação sob a forma de uma obra fílmica, a rememoração e a testemunha dos observadores sucedem-se no transcorrer da exposição.

Moments transforma-se constantemente; ela nunca é estável. Os suplementos, as subtrações, os deslocamentos, as reconfigurações intervêm sempre. Um processo ininterrompido de fabricação de novos documentos é instaurado desde o início. Por exemplo, durante o "Act - Stage and Display" [Ato-Palco e Exibição], as conferências e os ateliês dados pelos artistas são gravados e as captações adicionadas logo no espaço de exposição.

\section{Uma comunidade intergeracional e dissensual}

Moments é intergeracional. Ela põe em diálogo três gerações diferentes (as dez artistas mulheres, os dez participantes no laboratório, os dez estudantes testemunhas) chamadas para trabalhar juntas, em frente de um público ele mesmo intergeracional e segundo um jogo complexo de mediações. Cada geração é chamada a testemunhar diante dos outros: os artistas testemunham a sua experiência ao lado dos participantes do laboratório e dos estudantes; os estudantes testemunham das narrativas dos artistas ao lado do público e dos participantes do laboratório, sob os olhos dos artistas, pois eles testemunham do conjunto da sua experiência ao lado do público e de diversos grupos de visitantes; os participantes do laboratório reativam os documentos em frente dos artistas e dos estudantes, e diante da câmera de Sela (que intitulará o seu filme Witness [Testemunha]). Nessa situação dialogal complexa, a figura da testemunha é central. A testemunha empresta a voz dela aos outros e testemunha em frente de alguém. Ela tem uma responsabilidade ética em relação ás pessoas ao nome de quem ela fala e em relação aos quais e as quais ela se direciona. Essa responsabilidade moral é particularmente palpável durante o Open Lab ${ }^{11}$ que vinha encerrar a fase do laboratório. Ao longo de uma visita guiada atípica, pontuada pela frase "Only some of the actions are documented and only some of the documents are here" [Somente algumas das ações são documentadas e somente alguns dos documentos estão por 
aqui] declamada em coro, os estudantes comentam o material exposto, restituindo e apropriando-se das narrativas e das falas que lhes foram divulgadas pelos artistas, esses últimos os escutando no meio do público. Assim, uma estudante restitui a narrativa de Graciela Carnevale a respeito da sua ação The Enclosure [A cerca] , uma outra se lança numa aula de dança de funk diante do vídeo Funk Lessons (1983) [Aula de Funk] de Adrian Piper e sob o olhar do artista.

Moments cria uma comunidade intergeracional, pontualmente reunida em torno da transmissão das obras performativas do passado. Longe de se contentar em torno de consensus, esse corpo coletivo torna-se rapidamente dissensual, seus membros devem tomar sempre posição, uns em relação aos outros. Moments suscitou vários desacordos. Alguns artistas estavam abertos para a ideia dos seus documentos serem manipulados, outros não. Assim, Lynn Hershman Lyson ficou muito contrariada com a utilização do vestido e da peruca de Roberta Breitmore, o famoso alter ego que ela tinha inventado e encarnado em São Francisco nos anos 1970, contra a sua vontade durante ações e performances improvisadas no decorrer do laboratório. Além disso, o vestido emprestado pela galeria da artista ficou danificado. Hershman Lyson tinha exposto esses artefatos como relíquias e tinha pedido explicitamente que eles não fossem usados, uma postura que vários membros do laboratório criticaram. $\mathrm{O}$ pessoal do museu e a equipe curatorial se sentiram perdidos pela situação que eles mesmos tinham preparados. Para garantir a segurança dos documentos e dos objetos, sendo vários deles emprestados por coleções institucionais e privadas, eles tinham de controlar e limitar o uso que era feito deles.

Várias tensões foram igualmente palpáveis no meio dos membros do laboratório. Alguns deles consideravam que a exposição dos arquivos era suficiente. Ao invés de "atuar" os documentos, como eles eram convidados a fazê-lo, eles teriam optado de preferência por conferências e discussões com alguns "expertos". Dito de outra maneira, mais tradicional, eles teriam desejado a transmissão de um saber já constituído. Alguns outros, ao contrário, julgavam pertinente de "performar" os documentos, mas lamentavam o lugar muito importante da improvisação, certo descuido e a ausência de auto-avaliação, em relação à qualidade das propostas que emergiram.

Essas discordâncias foram expressas no catálogo mediante depoimentos ás vezes muito virulentos. Ao invés de privilegiar um único ponto de vista, o dos organizadores, a publicação 
dá a palavra a todos os protagonistas e desdobra, portanto, perspectivas contraditórias, sem procurar atenuar as fricções (GAREIS, SCHÖLLHAMMER et WEIBEL, 2013).

\section{O repertório: os suplementos, o diagrame e o corpo}

O que propunha a concepção da transmissão Moments? Ela opera segundo o regime do repertório que se apoia sobre a tríade seguinte: um fenômeno de apagamento por acumulação de adicionais; um deslocamento do arquivo ao diagramático; um lugar central dedicado ao corpo, ao vivo e aos afetos.

Moments engendra cadeias infinitas de adicionais que, acumulando-se, instalam paradoxalmente uma distância cada vez maior com as performances "originais". Isso também vale para Face Tunes (1967) de Simone FORTI. Definitivamente revolvida e inacessível, a performance de 1967 encontra-se convocada através dos fragmentos materiais que foram conservados e que são expostos. Esse frágil corpus de origem é completado pelo livro de artista, Handbook in Motion [Manual em movimento] (1974), que Forti publicou a respeito das suas obras, inclusive Face Tunes. Um filme documentando a "reconstrução" da performance de 2012 pela artista ela mesma, brincando num monitor. No quadro do ateliê organizado durante a primeira fase de Moments, Forti reinicia a performance da peça. Durante o laboratório, a coreógrafa Meg Stuart realiza depois uma performance na qual ela integra as imagens da reconstrução de 2012 e toca com a flauta de Forti, acompanhada do músico Burkhard Stangl. A prestação é filmada e várias sequências são integradas ao filme Witness de Sela e aos vídeos documentais da exposição.

Assim, as cadeias infinitas são estabelecidas e os efeitos desses encadeamentos são paradoxais: as performances do passado afastam-se pouco a pouco, quando os documentos, as narrativas e as reativações acumulam-se e se sobrepõem cada vez mais. Esse fenômeno de apagamento por acumulação consiste em que Rosalind Krauss e Amelia Jones chamam o "suplemento documental"; a primeira em relação à documentação do Land Art, a segunda sobre as performances e os documentos do "body art" (KRAUSS, 1993 ; JONES, 1997). Segundo Jacques Derrida, ao qual ambas as críticas referem-se, o adicional é um "encadeamento infinito, multiplicando inelutavelmente as mediações adicionais que produzem o sentido do que elas mesmas diferem: a miragem da coisa própria, da presença imediata, da percepção originária." (DERRIDA, 1967, p. 226) E Derrida acrescenta que o adicional é 
uma "ameaça terrificante na sua manifestação da ausência e da falta, mas "também a primeira e a mais segura proteção contra essa mesma ameaça. É por isso que é impossível desistir dela” (DERRIDA, 1967, p. 222).

O segundo aspecto que caracteriza o regime do repertório e que é central em Moments consiste no deslocamento do arquivo ao diagramático. Como as retomadas de Nachbar, de Bozić e de Le Roy evocadas no início dessa conferência, a exposição instaura uma dialética do arquivo e do diagramático. Ela aproxima o arquivo do diagramático. Várias atividades propostas durante o laboratório ou no quadro das atividades de mediação são manifestadas.

No obstante o fato que eles se sejam emoldurados e pendurados nas paredes, os desenhos-padrões da série Sonakinotography de Channa Horwitz não perdem, no entanto, a sua função de notação. Essas grades coloridas e minimalistas, respondem a uma lógica matemática baseada no número 8. De aparências muito rígidas, elas permitem de reproduzir uma infinidade de variações sonoras, musicais ou coreográficas. A artista explicita o funcionamento delas e Charmatz propõe aos seus acólitos de retocar as obras do conjunto da exposição, ativando uma das partituras. Os participantes se deslocam através dos compartimentos de uma grade traçada no chão, transposição do diagrama de Horwitz, e no meio deles, interpretam sucessivamente uma das obras dos artistas da exposição, segundo as sequências de sessenta tempos, conformeás prescrições da anotação. Não somente o diagrama de Horwitz encontra-se assim reativado, mas ele permite ligar todas as peças da exposição sem propor por enquanto uma narrativa histórica da arte da performance. Desse modo, Moments funciona não como uma coleção de documentos de arquivos, mas segundo o modelo de partitura e coreografia explorado por Le Roy em Retrospective [Retrospectiva], por exemplo.

Enfim, e isso é o terceiro aspecto do repertório, Moments coloca o vivo e a corporeidade no coração do processo de transmissão. A exposição confronta o regime do arquivo e do museu aos corpos, com todos os seus transbordados. Isso foi muitas vezes repetido, a corporeidade foi excluída das instituições das histórias da arte. O modelo do White Cube manifesta esse apagamento. Os espaços de difusão da arte são concebidos para espectadores reduzidos a um olho, e que mantêm junto com as obras uma relação de pura contemplação visual, dos sujeitos sem corpos, sem sexo, sem desejo. Isso é um dos motivos da exclusão das práticas performativas das vanguardas e das novas vanguardas da história da arte hegemônica. 
Moments, e particularmente a fase do laboratório, busca introduzir de novo o corpo: a sexualidade, a nudez, os afetos, os sobressaltos, o suor, o rir, etc.

Os participantes multiplicam as estratégias para "esfregar" os corpos aos arquivos. Assim, Meg Stuart, cuja linguagem coreográfica baseia-se sobre os estados de corpo que ela transmite aos dançarinos, através de exercícios, organiza sessões de risada no meio da exposição e dos documentos. Ou ainda, a conferência do arquiteto Nikolaus Hirsch, Object vs People, trata da incompatibilidade entre a preservação dos objetos nos museus que requerem um controle stricto do nível de umidade e o metabolismo dos corpos dos visitantes ou dos funcionários que rejeitam o calor e o vapor d'água. De modo mais provocativo, Charmatz e Jan Ritsema se masturbam ao lado das imagens de City Dance de Anna Halprin. Podemos ainda mencionar a interpretação, bunda nua, do Trio A, desajeitadamente realizada, olhando o filme de 1978 e reproduzindo em mímica os gestos de Rainer. Essa presença do corpo em todos os seus transbordamentos de afetos, de desejos, e seu confronto com a ordem asséptica do museu constitui o próprio coração do filme de Sela.

Se alguns desses gestos podem parecer tão provocantes, no entanto, eles não são menos portadores da memória de outros gestos: a masturbação de Vita Acconci escondido sob o chão falso da galeria Sonnabend, em Seedbed [Semente de cama] de 1972; as múltiplas retomadas do Trio A, uma em particular, de 1970, na Judson Church, na qual os intérpretes dançavam nus com as bandeiras estadunidenses. Em Moments, as evocações de todos esses gestos artísticos que tinham sido repetidos ao longo dessas últimas décadas, mesmo que muitas vezes vagas, nos lembram que o corpo é portador da memória das obras.

O apagamento por acumulação de adicionais, o deslocamento do arquivo ao esquemático, o lugar central dedicado ao corpo e ao vivo caracterizam o regime da transmissão privilegiada em Moments e provém do repertório. Não redutível a uma lista fechada de obras disponíveis, o repertório traz a ideia de criação (a sua etimologia reperire significa descobrir). Ele é evolutivo, expansivo, dinâmico e, sobretudo, criativo porque autoriza uma multidão de combinações. Ao invés de uma coleção ou de um patrimônio que nós conservamos, o repertório espera ser atuado de novo, reposto em jogo, reciclado, recriado, atualiza$\mathrm{do}^{12}$. Ele recorre tanto a um saber corporal, que Howard Becker chama de "repertório em ação" (BECKER et FAULKNER, 2009) e que Diana Taylor encara como "uma memória encarnada", um conjunto de gestos transmitidos pelo corpo, através das práti- 
cas vivas, segundo um processo de repetições e de diferenças (TAYLOR, 2003). Essa concepção do repertório seria plenamente operatória no contexto de um museu de arte contemporânea dedicado à criação artística, à sua difusão e à sua preservação?

\section{Uma experiência enganosa?}

Enquanto a dialética do arquivo, do diagrama e do vivo em Nachbar, Le Roy ou Bozić, produz obras novas, destacadas dos seus "originais" (e da ideia do original), Moments é enganosa sob um ponto de vista estético. Ficamos voluntariamente no registro do ensaio, da prática, do "esboço" ${ }^{\text {׳3 }}$.Parecemos nos deleitar num tipo de improdutividade no plano da criação. A única obra realizada ao longo dessa experiência e apresentada enquanto tal é o filme $\mathrm{Wi}$ tness de Sela, signo de uma vontade deliberada de inverter a economia tradicional da exposição. Aqui, só o documento faz obra. Moments é igualmente enganosa do ponto de vista da história da arte da performance, quer dizer, da escrita de uma narrativa e de uma contribuição científica para um saber histórico. Ao contrário do que seu título parecia prometer, "uma história da performance em dez atos", Moments não elabora nenhuma narrativa histórica. Quanto ao catálogo, ele oferece deliberadamente nenhuma síntese. Ele reflete mais o caráter processual e dissensual da experiência.

Improdutividade nos planos artísticos e científicos, conflitos entre os protagonistas. Podemos ao mesmo tempo concluir que Moments é um fracasso? De jeito nenhum se considerarmos as questões que estão abordadas a respeito da instituição do museu enquanto lugar de transmissão das obras performativas e coreográficas. Apesar das suas discordâncias, todos os atores envolvidos buscaram trabalhar (sobre) os limites do museu. Este poderia integrar o regime do repertório e sua tríade adicional/diagrama/corpo que discutem o seu mandato de coleção e de preservação? O que pode fazer um corpo num museu? Qual é a viabilidade de uma proposta curatorial que apoia-se sobre a dispersão, a descentralização, obviamente com os seus tempos mortos e as dificuldades de orientação pelos visitantes? O conceito de museu performativo, e a renúncia que ele implica em relação à difusão dos conhecimentos pode ser sustentável ao nível institucional e pragmático? 
3. Momentos. A história da performance em 10 atos, exposição organizada pelos curadores Boris Charmatz, Sigrid Gareis e Georg Schölhammer no Zentrum für Kust und Medientechnologie (ZUM) à Karlsruhe (8 de março - 29 abril 2012).

4. Movimento. Coreografando você. Arte e Dança desde os 1980, exposição itinerante organizada pela comissária Stephanie Rosenthal e sucessivamente apresentada na Hayward Gallery, Londres (13 de outubro 2010 - janeiro 2011), na Haus der Kunst, Munique (1o de fevereiro - 15 de maio 2011) e na Kunstsammlung Nordrhein - Westfalen, Düsseldorf (16 julho - 25 setembro 2011).

5. Dançar a vida. Arte e dança de 1900 aos nossos dias, exposição organizada pelos curadores Christine Macel e Emma Lavigne, Museu nacional de arte moderna, Centro nacional de arte e de cultura Georges Pompidou, Paris (23 novembro 2011 - 2 abril 2012).

6. O Quatuor Knust é um coletivo de quatro dançarinos que reinterpretam as obras do repertório moderno graça ao sistema de notação do movimento: Dominique Brun, Simon Hecquet, Christophe Wavelet, Ảnne Collod.

7. Retrospectiva de Xavier Le Roy, exposição inicialmente apresentada na fundação Antoni Tàpies, em Barcelona (24 de fevereiro - 22 abril 2012), depois sucessivamente em Rennes, Salvador na Bahia, Hambourg, Rio de Janeiro, Singapour, Paris e Nova Iorque.

8. Rehearsing Collectivity. Choreography Beyond Dance, exposição organizada pelas curadoras Elena Basteri, Emanuele Guidi e Elisa Ricci em Tanzfabrik, Berlim (27 de abril - 6 de maio 2011)

9. As quatro fases se desenrolam respectivamente nas seguintes datas: 8 - 17 março 2012; 18 - 30 de março 2012; 31 de março - 14 de abril 2012; 15 - 29 de abril 2012.

10. Alex Baczynski-Jenkins (coreógrafo e intérprete) Christine De Smedt (coreógrafa), Nikolaus Hirsch (arquiteto), Lenio Kaklea (coreógrafo), Jan Ritsema (diretor de palco), Gerald Siegmund (teórico da dança e do teatro), Burkhard Stangl (guitarrista), Meg Stuart (coreógrafa).

11. O Open Lab ocorreu em 30 de março de 2012.

12. Eu retomo aqui as reflexões de autores que, apesar dos campos disciplinarias muito diferentes dos quais eles resultaram (musica, teatro, performance, literatura, etc.), insistem sobre a instabilidade do repertório (POURADIER, 2013 ; LITVAN et LOPEZ IZQUIERDO, 2007 ; BIET, SCHECHNER, 2014).

13. Para retomar um termo de Charmatz que intitulou "esboço" uma serie de "exposições em movimento" realizada pelo Musée de la danse emcolaboração com os museus de arte.

\section{Referências}

AGAMBEN, Giorgio. La communauté qui vient. Théorie de la singularité quelconque. Traduit de l'italien par Marilène Raiola. Paris: Seuil, coll. Librairie du XXe siècle, 1990.

BASTERI, Elena ; GUIDI, Emanuele et RICCI, Elisa (dir.). Rehearsing Collectivity. Choreography Beyond Dance. Berlin : argobooks, 2012.

BECKER, Horward et FAULKNER, Robert. Do You Know...? 
The Jazz Repertoire un Action. Chicago : University of Chicago Press, 2009.

BIET, Christian et SCHECHNER, Richard. Reprendre les performances de l'Avant-Garde. Agôn, $\mathrm{n}^{\circ}$ 6, « La reprise comme monument », 2014. Disponível em :< http//:agon.enslyon.fr/ index.php ?id=2778>. Acesso em : 2 fev. 2015.

CHARMATZ, Boris.Manifeste pour un Musée de la danse. 2009. Artigo disponível em: <http://www.museedeladanse. org/fr/articles/manifeste-pour-un-musee-de-la-danse $>$. Acesso em : 2 fev. 2015.

COPELAND, Mathieu et PELLEGRIN Julie (dir.). Chorégraphier l'exposition. Dijon, Les presses du réel, coll. Nouvelles scènes, 2013.

DELEUZE, Gilles. Foucault. Paris, Éditions de Minuit, coll. Critique, 1986.

DELEUZE, Gilles. Francis Bacon. Logique de la sensation. Paris : La Différence, coll. La vue le texte, 1981.

DERRIDA, Jacques. Ce dangereux supplément... In : De la grammatologie. Paris: Éditions de Minuit, coll. Critique, 1967.

GAREIS, Sigrid ; Schöllhammer, Georg et Weibel, Peter. Introduction. Event - Trace - Context. On the Relevance of Historical Performance in the Exhibition Space. In : GAREIS, Sigrid ; SCHÖLLHAMMER, Georg et WEIBEL, Peter (dir.). Moments. A History of Performance in 10 Acts. Catalogue d'exposition. Karlsruhe: Zentrum für Kunst und Medientechnologie, Cologne, Éditions et librairies Walther König, 2013, p. 354-356.

GENETTE, Gérard. L'Euvre de l'art. Immanence et transcendance. Paris: Seuil, coll. Poétique, 1994.

GEORGIEVA, Angelina ; BASTERI, Elena et GUIDI, Emanuele.Guest Interview: Rehearsing Collectivity. In : dianadamian.com | Art Criticism, mai 2011. Disponível em:< http:// dianadamian.com/?p=769>. Acesso em: 2 fev. 2015.

GOODMAN, Nelson. Languages of Art: An Approach to a Theory of Symbols. Indianapolis: Bobbs-Merrill, 1968.

HECQUET, Simon et PROKHORIS, Sabine. Fabriques de la danse. Paris: Presses Universitaires de France, 2007.

HIRSCH, Nikolaus_Object vs People. In: expo zéro - online catalogue. Rennes, Musée de la danse, 2011. Disponível em: < http:// expozero.museedeladanse.org/le-catalogue.php?page $=9>$. Acesso em: 2 fev. 2015.

JONES, Amelia. "Presence" in Absentia: Experiencing Performance as Documentation. In : Art Journal, v. 56, n 4, 1997, p. 11-18. 
KRAUSS, Rosalind. Notes sur l'index. In : Le Mythe de l'avantgarde et autres mythes modernistes. Trad. Jean-Pierre Criqui. Paris: Macula, 1993, p. 65-91.

LEPECKI, André. The Body as Archive: Will to Re-Enact and the Afterlives of Dances. In : Dance Research Journal, v. 42, n. 2, 2010, p. 28-48.

LITVAN, Valentina et LOPEZ IZQUIERDO, Marta. Répertoire(s). Mode d'emploi. In : Pandora, $\mathrm{n}^{\circ}$ 7, « Répertoires », 2007, p. 9-17.

NANCY, Jean-Luc. La communauté désœuvrée. Paris: Christian Bourgois, coll. Détroits, 1986.

PHELAN, Peggy. The Ontology of Performance: Representation without Reproduction. In :Unmarked: The Politics of Performance. Londres et New York, Routledge, 1993, p. 146-166.

POURADIER, Maud. Esthétique du répertoire musical. Une archéologie du concept d'œuvre. Rennes : Presses universitaires de Rennes, 2013.

TAYLOR, Diana. The Archive and the Repertoire: Performing Cultural Memory in the Americas. Durham: Duke University Press, 2003.

WAVELET, Christophe et RASSEL, Laurence. Conversation. In : CVEJIĆ, Bojana (dir.). "Rétrospective " par Xavier Le Roy. Dijon: Les presses du réel, 2014, p. 33-48.

Recebido em: 10/o6/15

Aceito em: 01/o8/15 


\section{ANNE BÉNICHOU}

benichou.anne@uqam.ca

É professora de História e de teoria da arte na École des arts visuels et médiatiques da Université du Québec à Montréal. Suas pesquisas investigam as questões dos arquivos, das formas memorias e das narrativas históricas que resultam das praticas artísticas contemporâneas e das instituições responsáveis pelas suas preservações e suas difusões. Ela trabalha notavelmente sobre a memoria e a transmissão das obras efêmeras e performativas. Ela dirigiu as publicações coletivas Ouvrir le document. Enjeux et pratiques de la documentation dans les arts visuels contemporains e Recréer/Scripter. Mémoires et transmissions des œuvres performatives et chorégraphiques contemporaines(Les presses du réel, Dijon, 2010 et 2015); Ela é autor dos livros Muntadas. Between the Frames: the Forum (Museu d'Art Contemporani de Barcelona, 2011) eUn imaginaire institutionnel. Musées, collections et archives d'artistes (L'Harmattan, Paris, 2013). 